\title{
Percepções de Estudantes sobre o Debate das Relações Raciais na Formação em Psicologia
}

\author{
Students' Perceptions about the Debate on Racial Relations in the Psychology Bachelor Degree \\ Percepciones de los Estudiantes sobre el Debate de las Relaciones Raciales en \\ la Formación en Psicología
}

\section{Jamille Georges Reis Khouri}

Psicóloga graduada pela Escola Bahiana de Medicina e Saúde Pública. Mestranda em Psicologia da Educação pela PUC-SP. E-mail: jamillekhouri@hotmail.com

\section{Marilda Castelar}

Psicóloga, Mestre em multimeios pela Unicamp, Doutora em Psicologia Social pela PUC-SP. Professora Adjunta da Escola Bahiana de Medicina e Saúde Pública. E-mail: marildacastelar@gmail.com

\section{Resumo}

O presente estudo discutiu a presença e qualidade do debate sobre relações raciais em um curso de Psicologia de Salvador-Bahia. Objetivou também conhecer as percepções dos estudantes negros de Psicologia sobre o debate de relações raciais na formação e suas repercussões. O método de estudo qualitativo contemplou uma revisão bibliográfica e uma pesquisa de campo. Foi aplicado um questionário para seleção dos participantes e foram entrevistados nove estudantes que se autodefiniram como negras/os. As entrevistas foram gravadas em áudio, transcritas, e seus conteúdos foram analisados. Como resultado, observou-se que o debate sobre as relações raciais vem ocorrendo na graduação, porém ainda de maneira tímida e pontual, muitas vezes associado a iniciativas individuais de alguns professores que possuem alguma sensibilidade com o tema. Conclui-se a necessidade de se intensificar as discussões sobre as relações raciais na formação em Psicologia e de realizar novos estudos.

Palavras-chave: relações raciais, educação, formação, Psicologia.

\section{Abstract}

The present study discussed the presence and quality of the debate about racial relations in a Psychology undergraduate course at Salvador-Bahia. Its objective was also to know the perceptions of black Psychology students about the racial relations debate in their courses and its repercussions. The qualitative study method embraced a bibliographic review and a field research. A questionnaire to select the participants was applied, and nine students were interviewed, for they identified themselves as black. The interviews were recorded in audio, transcribed, and their content was analyzed. As a result, it was observed that racial relation debate has been occurring at the undergraduate level, however still in a punctual and shy manner, many times related to individual initiatives taken by a few professors, which have sensibility for the theme. The conclusion leads to the necessity of intensifying discussions about racial relations in the Psychology undergraduate level and performing further studies.

Keywords: racial relations, education, undergraduate level, Psychology. 


\section{Resumen}

El presente estudio discutió la presencia y cualidad del debate sobre relaciones raciales en una carrera de Psicología de Salvador-Bahía. Objetivó también conocer las percepciones de los estudiantes negros de Psicología sobre el debate de relaciones raciales en la formación y sus repercusiones. El método de estudio cualitativo contempló una revisión bibliográfica y una investigación de campo. Se aplicó un cuestionario para la selección de los participantes y se entrevistó nueve estudiantes que se auto declararon como negros(as). Se grabaron las entrevistas, se transcribieron los audios y se analizaron sus contenidos. Como resultado, se observó que el debate sobre las relaciones raciales está sucediendo en el pregrado, aún de manera tímida y puntual, muchas veces asociado a las iniciativas individuales de algunos profesores que tienen alguna sensibilidad con la temática. Se concluye la necesidad de intensificarse las discusiones sobre las relaciones raciales en la formación en Psicología y de realizar nuevos estudios.

Palabras-clave: Relaciones raciales, Educación, Formación, Psicología.

O presente artigo faz parte do projeto "Dimensões subjetivas das relações raciais na educação: histórias de vida de estudantes de Psicologia", no campo de estudos sobre memória, cultura e subjetividade. O mesmo buscou discutir as percepções dos estudantes de Psicologia sobre a presença do debate das relações raciais na graduação, bem como refletir sobre as repercussões dessa discussão para a formação da/o psicóloga/o.

O racismo, enquanto instrumento ideológico, foi utilizado para justificar a dominação de determinados grupos sobre outros, marcando o processo sócio-histórico de construção da sociedade brasileira. Para dificultar ainda mais a emergência do debate sobre o racismo e suas problemáticas, surgiu outra ideologia, denominada "democracia racial", que, ao disseminar a ideia de que não existe preconceito étnico-racial no Brasil, tornou comum a desqualificação das ocorrências e repercussões do racismo (Munanga, 2005).

A Psicologia como ciência, também contribuiu, ao longo de sua história, para a propagação de ideias racistas. Ainda hoje, escutamos relatos que denunciam a dificuldade dos profissionais de Psicologia em reconhecerem o racismo como causa de sofrimento psíquico. Diante de tal contexto, o Conselho Federal de Psicologia instituiu a Resolução $n^{\circ}$ 018/2002, que visa orientar a/o psicóloga/o sobre a sua prática perante o preconceito e a discriminação racial. Além dessa, existem outras leis e diretrizes no campo da educação que reiteram a importância e obrigatoriedade do ensino e debate das relações raciais nos cursos de nível superior.

Realizar esta pesquisa em um curso de Psicologia, portanto, foi uma forma de provocar reflexões e abrir portas para o debate sobre essa e outras problemáticas da sociedade brasileira, já que a/o psicóloga/o se depara, constantemente, no seu exercício profissional, com o sofrimento psíquico oriundo do racismo e da estrutura social vigente. É fundamental que a Psicologia se imponha como uma ciência comprometida com as demandas da sociedade contemporânea, incentivando sujeitos a se reconhecerem como ativos e responsáveis pelo mundo em que vivemos (Bock \& Gonçalves, 2009).

\section{0 racismo no Brasil e suas repercussões}

Sabemos que a ideia de raça só faz sentido enquanto construção teórica, porém, no Brasil, as repercussões de estudos científicos importados da Europa nos séculos XIX e XX, utilizados para justificar a escravidão e a hierarquia social, ainda permeiam as relações sociais (Martins, Santos, \& Colosso, 2013). Dessa forma, características fenotípicas, tais como cor da pele, textura do cabelo, formato dos lábios e do nariz são associadas a aspectos psíquicos, intelectuais e 
morais, diferenciando os grupos raciais - brancos e negros - e tornando o racismo uma problemática social (Schucman, Nunes, \& Costa, 2015).

O mito da democracia racial, mecanismo utilizado para invisibilizar as desigualdades raciais no Brasil, é outro importante aspecto para compreender a complexidade dessa temática. Esse mito nos cega em relação às violências geradas cotidianamente pelo racismo, além de nos fazer reproduzir discursos de culpabilização aos negros e negras pelas discriminações a que estão submetidos (Mayorga, 2013). A difusão dessas ideias também dificulta a identificação da ideologia do branqueamento, processo que coloca o branco em lugar de privilégios, tornando-o ideal de referência de toda uma espécie (Bento, 2012).

O racismo se constitui, assim, como um dos principais marcadores de desigualdades materiais e simbólicas vivenciadas pelo brasileiro. O processo de socialização e construção de subjetividades dos negros, brancos, pardos e indígenas se dá

\section{Psicologia e relações raciais}

A Psicologia, historicamente, contribuiu na construção de pensamentos racistas, principalmente ao longo do século XIX e início do século XX, quando influenciou na produção de conhecimentos baseados no racismo científico (Chaves, 2003; Antunes, 1998 citado por Mayorga, 2013). Nas últimas décadas, visando à desconstrução desses ideais, a Psicologia vem produzindo importantes referenciais teóricos sobre o tema, revelando os aspectos subjetivos das relações raciais e o sofrimento psíquico vivenciado por negros e negras (Schucman et al., 2015). Apesar disso, os trabalhos sobre Psicologia e relações raciais ainda não alcançam, em termos quantitativos, os trabalhos e pesquisas sobre outros temas tradicionais da área, além disso, não sabemos quais tem sido as repercussões dessas produções na formação e na atuação dos profissionais de Psicologia (Mayorga, 2013).

É importante demarcar que a ciência psicológica negou e ainda nega os aspectos atravessado pelas relações de poder, "estruturando as condições e possibilidades de trabalho, de estudo, de vínculo, de liberdade, de lugar onde morar e a forma de morrer" (Schucman et al., 2015, p. 2). Para os afrodescendentes, esses processos ocorrem de maneira violenta, pois são permeados pela objetificação dos seus corpos, pela imaginária inferioridade biológica, moral e intelectual, e pela valorização do negro como um ser folclórico (Andre, 2007).

Entende-se, portanto, o racismo como fonte de violação de direitos da população negra, bem como produtor de sofrimento psíquico e humilhação social (Santos, Gomes, Muñoz, \& Maia, 2015). Dessa forma, precisamos refletir de que forma a Psicologia vem contribuindo para a (des)construção de práticas preconceituosas. Será que a formação incentiva esses profissionais a atuarem com compromisso para a diminuição das desigualdades raciais?

históricos e sociais que permeiam o humano, construindo, portanto, teorias pautadas em uma lógica naturalizante e a-histórica, o que colabora com a construção de um saber conservador e comprometido com a manutenção de um status quo, impedindo a compreensão da subjetividade e do fenômeno psicológico de maneira crítica e, por conseqüência, a transformação social (Kahhale \& Rosa, 2009).

A partir dessa perspectiva, autores como Moura (2003) e Santos et al. (2015), propõem reflexões sobre como a/o psicóloga/o deve ser uma profissional preparada/o para identificar práticas racistas e preconceituosas, sendo capaz de propor discussões e problematizações em prol da igualdade. Os mesmos consideram ainda que as questões referentes às relações raciais emergem nos mais diversos contextos em que a/o psicóloga/o está inserida/o, como o clínico, organizacional, escolar, saúde, assistência social, serviços públicos etc., o que denuncia a necessidade de inclusão de 
estudos sobre diversidade, direitos humanos e relações raciais na grade curricular da formação em Psicologia.

Apesar da urgência, é raro encontrar nas grades curriculares dos cursos de graduação em Psicologia do Brasil alusão a temas referentes às relações raciais e ao racismo em disciplinas obrigatórias (Schucman, 2014; Schucman et al., 2015). Shucman (2014) justifica essa ausência com o fato de a formação em Psicologia ainda estar "centrada na ideia de um desenvolvimento psíquico humano igual entre os diferentes grupos racializados" (Shucman, 2014, p.85).

A invisibilidade dessa temática também fica evidente na pesquisa "Psicologia: Uma profissão de muitas e diferentes mulheres", publicada pelo Conselho Federal de Psicologia. Nesse estudo, apenas as psicólogas negras fizeram referência às relações entre gênero e raça, trazendo à tona questionamentos sobre quais as mulheres que estão tendo a oportunidade de ingressar no Ensino Superior, em especial na formação em Psicologia (Mayorga, 2013).

Considera-se que a Psicologia, como ciência e profissão, deve estar atenta aos processos relativos ao racismo, oferecendo suporte teórico e prático para a construção de instrumentos antirracistas e comprometidos com a transformação das relações sociais e econômicas (Schucman et al., 2015). Para tanto, é fundamental que a formação em Psicologia esteja engajada com ações afirmativas diversas, como o acesso e permanência da população negra no Ensino Superior (Mayorga, 2013). Movimentos como esses são fundamentais para romper com a Psicologia tradicional - surgida da elite para a elite - transformando estética e politicamente a cara da profissão.

\section{Leis e Diretrizes sobre o debate das relações raciais no Ensino Superior e na Psicologia}

No campo da educação, já é possível identificar alguns avanços legais no enfrentamento da discriminação étnico-racial. O primeiro deles é a lei 10.639/2003, que altera a lei de diretrizes e bases da educação nacional, lei no 9.394 , tornando obrigatório o ensino da história e cultura afrobrasileira e africana no ensino básico das redes pública e privada. Posteriormente, incluiu-se a obrigatoriedade do estudo da história e cultura indígena, por meio da lei 11.645/08.

Visando auxiliar, expandir e amparar a aplicabilidade dessa lei, alguns planos, diretrizes e resoluções foram estabelecidos:

a) Diretrizes curriculares nacionais para a educação das relações étnico-raciais e para o ensino de história e cultura afro-brasileira e africana, instituído em 2004;

b) Plano Nacional de Implementação das Diretrizes Curriculares Nacionais para a Educação das Relações Étnico-Raciais e para o Ensino de História e Cultura Afro-brasileira e Africana, lançado em 2009 pela extinta Secretaria Especial de Políticas de Promoção da Igualdade Racial (SEPPIR).

Esses documentos têm o objetivo de orientar a prática no campo da educação no que diz respeito à valorização da história e cultura afro-brasileiras e africanas, estabelecendo as atribuições dos diferentes níveis e modalidades de ensino, tais como Educação Infantil; Ensino Fundamental; Ensino Médio; Educação Superior; EJA e educação em áreas remanescentes de quilombos (Brasil, 2004; Brasil, 2009; Suleiman, 2014).

No que se que refere ao Ensino Superior, principal enfoque deste estudo, a Resolução $\mathrm{CNE} / \mathrm{CP} \mathrm{n}^{\circ} 01 / 2004$, em seu Artigo $1^{\circ}$, inclui nos conteúdos das disciplinas e nas atividades curriculares das instituições de Ensino Superior, pública e privada, a educação para as relações étnico-raciais em todos os cursos e não somente para a formação de professores. De acordo com o 
Plano Nacional de 2009, as instituições de Ensino Superior devem, portanto, assumir o compromisso com o desenvolvimento de atividades acadêmicas, encontros, seminários, jornadas sobre as relações étnico-raciais; promover pesquisas e inovações tecnológicas nessa temática, estimulando a criação de bolsas de iniciação científica; além de capacitar de maneira adequada os alunos dos cursos de licenciatura e formação de professores sobre a história e cultura afro-brasileiras e africanas, bem como para a construção e leitura crítica dos materiais didáticos.

No âmbito da Psicologia, destacam-se, como marcos regulatórios, o Código de Ética Profissional e a Resolução 018/2002. Esta foi construída com o intuito de estabelecer normas de atuação para os psicólogos em relação ao preconceito e à discriminação racial. Para tanto, ela afirma que os psicólogos deverão contribuir, por meio de seu conhecimento, para uma reflexão sobre o preconceito e para a eliminação do racismo, além de definir algumas posturas e ações que esse profissional não deve realizar ou compactuar. Apesar de essa resolução ser um importante avanço, autores como Santos et al. (2015) consideram que a mesma necessita de uma revisão, uma vez que os seus artigos estão mais direcionados para o que a/o Psicóloga/o não deve fazer, ao invés de propor e exemplificar de que forma o conhecimento psicológico pode ser utilizado em benefício do combate ao preconceito e discriminação racial e a promoção de igualdade.

Nesse sentido, pesquisar a presença e qualidade do debate sobre relações raciais, a partir das percepções dos estudantes de Psicologia, pode ser um caminho para um amadurecimento dessa prática em um futuro próximo.

\section{Método}

O presente estudo encontra-se no âmbito da pesquisa qualitativa, entendida por González Rey (2002) como uma forma de contraponto ao modelo positivista da ciência, por meio do estudo da subjetividade a partir de perspectivas pessoais, históricas e culturais das expressões humanas.

Para selecionar os participantes, estudantes que se autodeclararam negros, realizou-se, em uma primeira etapa, um mapeamento do perfil dos alunos matriculados, do primeiro ao décimo semestre de 2015.2, em um curso de Psicologia de uma faculdade particular de Salvador-BA. Para tal, foram aplicados questionários, contemplando perguntas fechadas e abertas referentes à autodefinição de cor/raça, bem como noções gerais sobre suas experiências com o debate sobre relações raciais na escola e na formação em Psicologia.

No total, 228 estudantes participaram da primeira etapa desta pesquisa, desse montante, 38 se autodefiniram como pretos. Em um segundo momento, após a análise qualitativa dos 38 questionários e eliminação dos componentes do grupo de estudos sobre relações raciais da instituição pesquisada, realizaram-se entrevistas semiestruturadas com nove estudantes de Psicologia (um por semestre) que se autodeclararam negros, sendo oito do sexo feminino e um do sexo masculino, com idades entre 18 e 25 anos.

As entrevistas foram gravadas em áudio, transcritas e conferidas, sendo objetos de leituras flutuantes para o processamento e definição de categorias de acordo com a análise de conteúdo (Bardin, 2009). A partir desse processo, emergiram percepções relevantes sobre o debate das relações raciais na formação em Psicologia.

É válido enfatizar que a presente pesquisa encontra-se aprovada em Comitê de Ética. Ademais, os participantes tiveram o sigilo nominal preservado, as entrevistas ocorreram em sala adequada para preservação dos entrevistados e a utilização dos questionários e das entrevistas semiestruturadas, gravadas em áudio, só ocorreu mediante a assinatura do Termo de Consentimento Livre Esclarecido (TCLE). 


\section{Resultados e Discussão}

A partir dos dados obtidos nos questionários e entrevistas, observa-se que as/os estudantes de Psicologia da instituição pesquisada consideram que o debate sobre as relações raciais vem ocorrendo na graduação, porém ainda de maneira tímida e insatisfatória, muitas vezes associada a iniciativas individuais de alguns professores que possuem afinidade e sensibilidade em relação à temática. Em resposta à questão fechada do questionário "Até o presente momento, você vivenciou alguma discussão sobre relações raciais no curso de Psicologia?", a maioria das/os estudantes $(91,7 \%)$ respondeu que sim, ou seja, de alguma forma as reflexões sobre o racismo e suas implicações estiveram presentes na formação desses futuros psicólogos. Cabe aqui pensarmos, entretanto, de que forma esse processo vem se dando, será que a forma como esse debate está aparecendo irá refletir concretamente nas práticas Psi?

\section{Percepções sobre o debate das relações raciais na formação em Psicologia}

Ao serem questionadas/os sobre a presença e qualidade do debate sobre relações raciais na formação em Psicologia, as/os entrevistadas/ os, de maneira geral, afirmaram que ele ocorre de maneira superficial nas salas de aula. Apesar disso, destacam a iniciativa de alguns professores e o grupo de estudos e pesquisa existente sobre o tema.

As discussões são superficiais, a gente não fala da sociedade em si, como é. A forma como se fala do racismo na faculdade é bem superficial, bem solta e a gente não trata das questões, acho que muito por causa do preconceito que a gente tem (...) $\left(\mathrm{E}_{6}, \mathrm{~F}, 25\right.$ anos).

Eu não acho que (o debate sobre relações raciais) ocorre de forma satisfatória, mas eu sei que tem grupos na faculdade, tipo o grupo de M., por exemplo, porém eu não vejo assim, algo nas disciplinas, entendeu? ( $\mathrm{E}_{8}, \mathrm{~F}, 22$ anos).

As falas acima revelam a ausência do debate sobre relações raciais nas disciplinas obrigatórias da formação em Psicologia, reiterando as afirmações de Schucman (2014) e Schucman, et al. (2015). A existência dessa discussão, portanto, fica condicionada ao movimento de alguns professores que possuem afinidade com a temática ou a existência de grupos de estudos e pesquisa, sendo válido ressaltar que, em uma cidade como Salvador, em que a maioria da população é negra, esse debate não pode continuar como opcional. Observa-se que, no contexto pesquisado, perspectivas tradicionais e críticas caminham lado a lado, evidenciando as contradições e tensões existentes nos espaços de educação. Essas contradições e tensões são molas propulsoras para a (des)construção de práticas no campo da formação em Psicologia. A entrevistada abaixo por exemplo, externa que a faculdade, mesmo não assumindo a temática das relações raciais de maneira consolidada em seu projeto político e pedagógico, foi o espaço que mais possibilitou reflexões sobre o tema, durante toda a sua trajetória:

Eu acho que tem professores que debatem, né? A gente teve com A., com M., a gente debateu bastante essas questões. Eu não sei se isso foi suficiente, mas já foi mais do que na minha vida toda ( $\mathrm{E}_{5}, \mathrm{~F}, 21$ anos).

O relato evidencia, portanto, que o escasso debate na educação básica torna ainda mais relevante esse tipo de discussão no Ensino Superior, já que para muitas pessoas esse contexto parece ser o único que poderá proporcionar reflexões sobre questões sociais e raciais.

Os recursos escolhidos pelos professores para discutir a temática racial em sala de aula é 
um dos pontos que merecem atenção. Uma das entrevistadas cita uma experiência marcante vivenciada na formação, em que a professora utiliza a arte, através de um filme, como mecanismo de reflexão:

Eu acho que no primeiro semestre A. bateu bastante nessa tecla, assim a gente fez vários trabalhos sobre racismo e ela passou um filme, Vênus negra, e a gente discutiu e tal, então foi um trabalho bem marcante, porque era sobre um sofrimento, a história de um sofrimento muito grande, né? ( $\mathrm{E}_{5}, \mathrm{~F}, 21$ anos).

Entender a história de sofrimento da população negra e a forma como a sua subjetividade é constituída são elementos relevantes para a atuação da/o psicóloga/o nos mais diversos contextos. A/o profissional de Psicologia deve ser capaz de identificar situações preconceituosas, propondo intervenções a favor da transformação social (Moura, 2003; Santos et al., 2015). Portanto, atividades como a descrita acima são de grande contribuição para a sensibilização da/o futura/o profissional de Psicologia.

Outro aspecto importante trazido por uma entrevistada foi o fato de que, independentemente de iniciativas da instituição, as relações interpessoais e os encontros entre as pessoas no ambiente acadêmico podem possibilitar discussões diversas e um maior suporte social:

(...) a graduação tem me dado sim um suporte diferencial, tem trazido discussões diferenciais, observações também, mas assim não pela instituição (...), mas pelo grupo que tá ali. Discussão até traz alguns professores pontuais, dá para você contar no dedo, é mais uma discussão assim da turma e não é uma discussão de $90 \%$ da turma e sim de 30\% da turma (...).

Considera-se que a troca de experiências e de estratégias de enfrentamento do racismo nos contextos educativos são de grande importância para os processos de aprendizagem, sendo também fundamentais para o desenvolvimento da consciência racial. $\mathrm{Na}$ atualidade, os alunos da faculdade pesquisada vêm construindo espaços alternativos de debate com o objetivo de acolher e dar visibilidade a temas pouco discutidos na grade curricular formal. Dessa forma, buscam fazer um enfrentamento, propondo intervenções dentro da instituição.

Também é importante destacar os avanços observados pelos entrevistados durante a sua formação. O aumento de alunos negros na instituição, por exemplo, foi um dos pontos destacados pelos entrevistados:

\section{(...) atualmente a faculdade está melhorando, vamos dizer assim, na quantidade de adoção [ingresso] de alunos negros. No entanto, isso ainda não se manifesta de uma forma que se você for pintar um quadro você faça um ponto negro, não dá, não dá para você fazer isso, é uma instituição elitista, sim, branca, sim, mas que tem uma abertura para a discussão, ela só não amplia essa discussão, para mim o grande defeito da instituição é esse ( $\mathrm{E}_{6}$, F, 25 anos).}

Eu acho que aumentou [a quantidade de negros na faculdade], melhorou desde que eu entrei, de 2012.2 para cá, porque logo quando eu entrei não encontrava muitos negros aqui, mas agora eu acho que aumentou ( $\mathrm{E}_{7}, \mathrm{~F}, 21$ anos).

O aumento de pessoas negras nas instituições privadas é fundamental para a promoção de inclusão racial, possibilitando nesses espaços uma maior diversidade étnico-racial, além de avanços nas condições socioeconômicas dessa população. Pode-se considerar que a ampliação do acesso ao Ensino Superior é fruto de ações afirmativas, como o FIES e o PROUNI, inclusive, a maioria dos entrevistados, no momento da pesquisa, eram beneficiados pelo FIES. É importante enfatizar que programas como esses dependem de condições externas e podem sofrer alterações, como redução e cortes, dependendo do cenário político em que o país se encontra. Além disso, ações que tem por objetivo ampliar o acesso de alunos negros 
e de baixo poder aquisitivo ao Ensino Superior necessitam caminhar em conjunto com programas de incentivo e permanência para que, de fato, possibilitem uma inclusão social.

O ingresso da população negra no Ensino Superior também gera um movimento de representatividade nas profissões. Na Psicologia, a pouca quantidade de profissionais negras/os, bem como a dificuldade de acesso das populações com baixa condição socioeconômica aos serviços psicológicos, constroem um imaginário social branqueado para essa ciência e profissão, o que fica evidente nas falas abaixo:

Eu estava falando com meu namorado outro dia que psicólogo conta muito caso clínico, quando as pessoas contam os casos eu não imagino pessoas negras, e eu sou negra e eu não imagino pessoas negras, então por que isso? Como que isso é construído? É porque a gente não se vê ( $\mathrm{E}_{5}, \mathrm{~F}, 21$ anos).

Eu já li vários artigos sobre a quantidade de psicólogas negras, onde estão trabalhando essas negras, fiquei chocada, na clínica você não vê uma psicóloga negra, você não vê (...) Pacientes que chegam e descobrem que ela é negra e cancelam. Por que não falar sobre isso? $\left(\mathrm{E}_{6}, \mathrm{~F}, 25\right.$ anos $)$.

Mayorga (2013), ao identificar a invisibilidade da temática racial na Psicologia, denuncia a pouca quantidade de profissionais negras/os, o que corrobora o exposto pelas entrevistadas. O fato de a maioria das/os psicólogas/os pertencerem ao grupo racial branco, que devido aos seus privilégios não se percebe racializado, pode ser considerado um dos fatores que tornam essa temática ausente na formação (Schucman, 2014).

Por fim, observou-se que as discussões sobre relações raciais na formação em Psicologia, mesmo que insuficientes, podem ser instrumentos de transformação pessoal e profissional. As entrevistadas abaixo passaram a se reconhecer como negras e a se dar conta do lugar que ocupam na sociedade a partir dos debates vivenciados na graduação:

Quando eu era criança, não era uma discussão presente na minha casa, eu acho que até demorei para me descobrir negra e para aceitar isso (...) Foi na faculdade, eu acho, foi mais na faculdade, porque as pessoas sempre falavam que eu era cabo verde: "Ah você é moreninha, mas vocên não chega a ser negra e tal", essa coisa, e aí quando a gente começou a discutir isso na faculdade que eu fui me tocando, né? ( $\mathrm{E}_{5}, \mathrm{~F}, 21$ anos).

Eu vim discutir sobre relações raciais agora na faculdade que veio assim um boom de informações e de coisas que eu nem tinha parado para poder pensar que existiam, ainda mais relacionado à mulher, mulher negra e diversas outras coisas que tem em relação à abordagem policial (...) ( $\mathrm{E}_{4}, \mathrm{~F}, 21$ anos).

Observa-se, portanto, que as iniciativas existentes na formação em Psicologia, mesmo que isoladas, têm o potencial de provocar mudanças na tomada de consciência de pessoas que não tiveram a oportunidade de discutir sobre relações raciais em outros contextos. É fundamental que os espaços de educação estejam atentos ao processo de tomada de consciência da população negra, bem como à sensibilização de pessoas brancas. Dessa forma, pode-se deduzir que um programa consistente, a nível institucional, sobre relações raciais poderia atingir brancos e negros de forma mais decisiva, o que seria de grande relevância na formação em Psicologia, já que esse profissional irá se deparar com as demandas oriundas do racismo nos mais diversos contextos de atuação.

\section{Considerações Finais}

As percepções das/os entrevistadas/os em relação ao debate sobre relações raciais na formação em Psicologia sugere o quanto essa discussão precisa ser intensificada, sem ocorrer apenas de 
maneira fragmentada, à mercê da iniciativa de alguns professores ou em grupos de estudos e pesquisa, mas sim sendo incorporada no projeto político e pedagógico da instituição de maneira mais ampla. Nesse sentido, é importante que haja uma capacitação dos professores, iniciada, por exemplo, por meio da sensibilização em eventos que envolvam todos os docentes, como os fóruns pedagógicos, e também em formações intensivas para aceleração desse processo.

A pesquisa de campo realizada nesse estudo é outro importante aspecto a ser pontuado. Considera-se que a aplicação dos questionários em grande número de estudantes de Psicologia matriculados na instituição pesquisada, gerou um movimento nesse contexto, se constituindo como uma forma de reflexão sobre a temática das relações raciais na formação de futuros profissionais de Psicologia que atenderão uma população local de maioria negra. As entrevistas também possibilitaram aos entrevistados a oportunidade de ressignificar experiências.

Ademais, pesquisas como essa podem servir como forma de sensibilizar a Associação Brasileira de Ensino em Psicologia (ABEP) para o investimento em formação específica de professores de Psicologia sobre o tema das relações raciais, já que a Resolução CFP n ${ }^{0}$ 18/2002 estabelece normas de atuação para os psicólogos em relação ao preconceito e à discriminação racial.

\section{Referências}

Andre, M. da C. (2007). O ser negro: um estudo sobre a construção de subjetividades em afrodescendentes (Tese de Doutorado). Instituto de Psicologia, Universidade de Brasília, Brasília. Recuperado de http://repositorio. unb.br/handle/10482/6471

Antunes, M. A. M. (1998). A Psicologia no Brasil: Leitura Histórica sobre sua Constituição. São Paulo: Educ/ Unimarco Editora.

Bardin, L. (2009). Análise de Conteúdo. Lisboa: Edições 70.

Bento, M. A. S. (2012). Branqueamento e branquitude no Brasil. In I. Carone \& M. A. S. Bento (Orgs.), Psicologia social do racismo (p. 25-57). Rio de Janeiro: Editora Vozes.

Bock, A. M. B., \& Gonçalves, M. G. M. (2009). A dimensão subjetiva dos fenômenos sociais. In A. M. B. Bock \& M. G. M. Gonçalves (Orgs.), A dimensão subjetiva da realidade: uma leitura sócio-histórica (p. 116-157). São Paulo: Cortez.

Brasil. Ministério da Educação (2004). Diretrizes Curriculares Nacionais para a Educação das Relações Étnico-raciais e para o Ensino de História e Cultura Afro-Brasileira e Africana. Brasília: Ministério da Educação/Secretaria de Educação Continuada, Alfabetização e Diversidade.

Brasil. Ministério da Educação (2009). Plano Nacional de Implementação das Diretrizes Curriculares Nacionais para a Educação das Relações Étnico-Raciais e para o Ensino de História e Cultura Afro-Brasileira e Africana. Brasília: SECAD; SEPPIR.

Brasil. Casa Civil (2015). Lei 10.639, de 9 de janeiro de 2003. Altera a Lei n ${ }^{\circ} 9.394$, de 20 de dezembro de 1996, que estabelece as diretrizes e bases da educação nacional, para incluir no currículo oficial da Rede de Ensino a obrigatoriedade da temática "História e Cultura AfroBrasileira”, e dá outras providências. Brasília. Recuperado de http://www.planalto.gov.br/ccivil_03/leis/2003/ L10.639.htm

Brasil. Conselho Nacional de Educação (2015). Resolução CNE/CP $n^{\circ}$ 01/2004. Institui Diretrizes Curriculares Nacionais para a Educação das Relações Étnico-Raciais e para o Ensino de História e Cultura Afro-Brasileira e Africana. Recuperado de http://portal.mec.gov.br/cne/ arquivos/pdf/res012004.pdf

Chaves, E. S.(2003). Nina Rodrigues: sua interpretação do evolucionismo social e da Psicologia das massas nos primórdios da Psicologia social brasileira. Psicologia em Estudo, 8(2), 29-37. Recuperado de http://www.scielo. br/pdf/\%0D/pe/v8n2/v8n2a03.pdf

Conselho Federal de Psicologia (2015). Resolução CFP $n^{o}$ 018/2002. Recuperado de http://site.cfp.org.br/wpcontent/uploads/2002/12/resolucao2002_18.PDF

González Rey, F. L. (2002). Pesquisa qualitativa em psicologia: caminhos e desafios. São Paulo: Pioneira Thomson Learning.

Kahhale, E. M. S. P, \& Rosa, E. Z. (2009). A construção de um saber crítico em Psicologia. In A. M. B. Bock \& M. G. M. Gonçalves (Orgs.). A dimensão subjetiva da realidade: uma leitura sócio-histórica. São Paulo: Cortez.

Martins, E., Santos, A. O., \& Colosso, M. (2013). Relações étnico-raciais e psicologia: publicações em periódicos da SciELO e Lilacs. Psicologia: teoria e prática, 15(3), 118-133. Recuperado de http://pepsic.bvsalud.org/ pdf/ptp/v15n3/09.pdf

Mayorga, C. (2013). Sobre mulheres, psicologia, profissão e a insistente ausência das questões raciais. In Conselho Federal de Psicologia (Org.). Psicologia: uma profissão de muitas e diferentes mulheres. Brasília: CFP. Recuperado de http://site.cfp.org.br/publicacao/psicologia-umaprofissao-de-muitas-e-diferentes-mulheres/ 
Moura, M. J. D. H.(2003). Atuação Profissional e Relações Raciais. In Conselho Federal de Psicologia (Org.). Os direitos humanos na prática profissional dos psicólogos. Brasília: CFP. Recuperado de http://site.cfp.org.br/wpcontent/uploads/2004/05/cartilha_dh.pdf

Munanga, K.(2005). Apresentação. In Munanga, K. (Org.). Superando o Racismo na escola. Brasília: Ministério da Educação, Secretaria de Educação Continuada, Alfabetização e Diversidade.

Santos, A. O., Gomes, L. B. S., Muñoz, B. L., \& Maia, R. L. A.(2015). Marcos regulatórios sobre relações raciais e racismo: instrumentos para atuação do(a) psicólogo(a). Revista Brasileira de Psicologia, 2, 16-27. Recuperado de http://revpsi.org/wp-content/uploads/2015/12/Santoset-al.-2015-Marcos-regulatórios-sobre-relações-raciais- e-racismo-instrumentos-para-atuação-doa-psicólogoa. pdf

Schucman, L. V.(2014). Sim, nós somos racistas: estudo psicossocial da branquitude paulistana. Psicologia \& Sociedade, 26(1), 83-94. Recuperado de https://dialnet.unirioja.es/servlet/ articulo? codigo $=4808565$

Schucman, L. V., Nunes, S. S., \& Costa, E. S. (2015). A Psicologia da Universidade de São Paulo e as relações raciais: perspectivas emergentes. Psicologia USP, 28(1), 1-15. http://doi.org/10.1590/0103-6564A20132413

Suleiman, B. B.(2014). Psicologia e Ensino das Relações Étnico-Raciais: uma experiência na formação de professores. Psicologia Escolar e Educacional, 18(2), 369372. doi: 10.1590/2175-3539/2014/0182809 